\title{
TELEHEALTH AND PSYCHIATRY. \\ IS THIS NEXT?
}

\author{
Authors: Noguero, A. ${ }^{1}$, Barahona, P.M. ${ }^{1}$, García, S. ${ }^{2}$, Galvañ, J. ${ }^{1}$, Parra, S. ${ }^{1}$ \\ ${ }^{1}$ Hospital Universitari Son Espases, Mallorca, Islas Baleares \\ ${ }^{2}$ Hospital Comarcal de Inca, Mallorca, Islas Baleares
}

\section{OBJECTIVE}

The aim of this review is to see what is being done today with psychiatry through technology.

MATERIAL AND METHOD

Bibliographic search in PubMed and Medline

\section{DISCUSSION}

Telepsychiatry has been applied to a wide variety of medical conditions and is used effectively in managing patient's mental health.

Randomized trials telehealth interventions are being done for patients with mental illness such as, detoxification, depression, schizophrenia or bipolar disorder.

Telehealth facilitates integrated, patient-centred care.

Studies show that synchronous video, telepsychiatry (TP), or telebehavioural health provide outcomes as good as in-person care. It also improves access to care, leverages expertise at a distance, and is effective for education and consultation to primary care.

Studies are preliminary, but those with collaborative and consultative care show effectiveness. Low- and mid-intensity technology options like telephone, e-mail, text, and e-consults, may provide better access for patients and more timely provider communication and education. Effective healthcare delivery matches the patients' needs with the model, emphasizes clinician competencies, standardizes interventions, and evaluates outcomes.

Telemedicine can deliver low-threshold support to patients who are otherwise at high risk of progressive nonadherence to their psychotropic medication after 6 months.

\section{BIBLIOGRAPHY}

1. Hilty, D. M., Sunderji, N., Suo, S., Chan, S., \& Mccarron, R. M. (2019). Telepsychiatry and other technologies for integrated care: Evidence base, best practice models and competencies. International Review of Psychiatry, 1-18. doi:10.1080/09540261.2019.1571483

2. Timko, C., Below, M., Vittorio, L., Taylor, E., Chang, G., Lash, S., . . Brief, D. (2019). Randomized controlled trial of enhanced telephone monitoring with detoxification patients: 3- and 6-month outcomes. Journal of Substance Abuse Treatment, $99,24-31$. doi:10.1016/j.jsat.2018.12.008

3. Doarn, C. R. (2018). Telemedicine and psychiatry-a natural match. MHealth, 4, 60-60. doi:10.21037/mhealth.2018.12.04

4. Schulze, L. N., Stentzel, U., Leipert, J., Schulte, J., Langosch, J., Freyberger, H. J., . . Berg, N. V. (2019). Improving Medication Adherence With Telemedicine for Adults With Severe Mental Illness. Psychiatric Services, 70(3), $225-228$. doi:10.1176/appi.ps.201800286 